\title{
Molecular detection of Anaplasma phagocytophilum DNA in Olive Baboons and Vervet monkeys in Kenya
}

Sophie Jerusa Masika ( $\square$ masikasophie10@gmail.com )

University of Nairobi

Gerald Mwangi Muchemi

University of Nairobi

Joseph Muiruri Kamau

Institute of Primate Research

Tequiero Abuom

University of Nairobi

Samson Kamawe Mutura

Institute of Primate Research

\section{Research Article}

Keywords: Zoonosis, Olive baboons, Vervet monkeys, Kenya, Anaplasma phagocytophilum

Posted Date: April 8th, 2021

DOl: https://doi.org/10.21203/rs.3.rs-355087/v1

License: (9) This work is licensed under a Creative Commons Attribution 4.0 International License.

Read Full License 

DNA in Olive Baboons and Vervet monkeys in Kenya.

\section{Sophie Jerusa Masika ${ }^{1}$, Gerald Mwangi Muchemi ${ }^{1}$, Joseph Muiruri Kamau ${ }^{2}$, Tequiero Abuom} Okumu $^{1}$, Samson Kamawe Mutura ${ }^{2}$

Affiliations of authors

${ }^{1}$ University of Nairobi, ${ }^{2}$ Institute of Primate Research

*Corresponding author. Tel., +254 724855 023, E-mail address: masikasophie10@gmail.com

\section{Abstract}

\section{Background}

Nonhuman primates (NHPs) occupy an important place in zoonotic spill-overs, serving as either reservoirs or amplifiers of multiple neglected tropical diseases including tick-borne infections. Anaplasmosis is caused by obligate intracellular bacteria of the family Anaplasmatacae. They are transmitted by Ixodid tick species and have a wide host range including wild animals, domestic animals and humans. The aim of this study was to establish the presence of Anaplasma phagocytophilum in Olive baboons and Vervet monkeys in Laikipia County, Kenya.

\section{Results}

A total of 164 whole blood samples, collected by USAID Predict II project from Laikipia County, Kenya, were included in the study. These comprised of 146 samples from Olive baboons (Papio anubis) and 18 from Vervet monkeys (Chlorocebus pygerythrus) respectively from Mpala Research Center and Ol jogi Conservancy in Laikipia County. Using conventional Polymerase Chain Reaction (PCR), positive results for A. phagocytophilum in 26 Olive baboons and 4 Vervet monkeys were detected with primer sets EHR16SD/R. However, low sensitivity was observed with the p44 gene. The amplification of DNA template with the primer set p44 (p3709 5/ p4257 5) using nested PCR could not be obtained. Our results revealed the presence of $A$. 
25 phagocytophilum in Olive baboons and Vervet monkeys. This study found an overall prevalence 26 of $18.3 \%$ for Anaplasma phagocytophilum. A distinct genotype of A. phagocytophilum was 27 detected that was different from the others in the gene bank database.

\section{Conclusion}

29 This study provides valuable information on the presence of A. phagocytophilum bacteria in Olive

30 baboons and Vervet monkeys in Kenya. It indicates a need for future research to establish the 31 public health implications of zoonotic A. phagocytophilum isolates and the role of nonhuman 32 primates as reservoirs.

33 Key words: Zoonosis, Olive baboons, Vervet monkeys, Kenya, Anaplasma phagocytophilum 


\section{$43 \quad$ Background}

44 There has been a rise in the frequency of emerging infectious diseases (EIDs), among which

45 zoonotic tick-borne infections especially rickettsial diseases such as anaplasmosis, are implicated

46 [1]. What most of the recent pandemics have proven is that emerging infectious diseases are mainly

47 of animal origin, particularly wildlife [2]. The complex interaction among wildlife, livestock and

48 human populations is a factor that contributes to their emergence [3].

49 Among wildlife species, non-human primates are often proprietors to different microbial agents

50 some which have zoonotic potential. Primates are closely related to humans phylogenetically and

51 ecologically [4] and they can indirectly transmit infectious agents to humans through intermediate

52 hosts, arthropod vectors or directly through bush meat consumption and accidental bites [5].

53 Certain factors such as forested tropical regions experiencing land-use changes and encroachment

54 as well as those with a high wildlife biodiversity facilitate the spread of these diseases to livestock

55 and man [6]. Others include adoption of new technology in farms, destruction of habitats, climate

56 change, travel and encroachment into new habitats [2].

57 This study focused on Anaplasma phagocytophium, a pathogenic bacterium of zoonotic potential

58 often spread among wildlife then to livestock and man [7]. Anaplasma hemoparasites belong to

59 the family of Anaplasmataceae, order of Rickettsiales, class Alphaproteobacteria and genus

60 Anaplasma [8]. However, reclassification of Anaplasma happened recently resulting in A.

61 phagocytophilum being included in the genus whose members were only pathogens with host

62 specificity to ruminants such as A. marginale. This followed advancement in genetic analyses of

63 16S rRNA genes, groESL and surface protein genes. There is a considerable strain variation with

64 A. phagocytophilum such that there appears to be existence of serological cross-reactivity [9], a 
65 minor degree of variation in the nucleotide sequences of the 16S rRNA, groESL, gltA, ank, and 66 msp2 genes [10] and a difference in the host infectivity [11].

67 This bacterium has a wide host range including domestic animals, wildlife and man [12]. In man 68 the disease is known as human granulocytic anaplasmosis (HGA) [13]. The disease often presents 69 with influenza-like symptoms in animal and human hosts which include fever, anorexia, diarrhea, 70 leukopenia and thrombocytopenia [7]. Ixodid ticks are important in their maintenance as vectors 71 [14]. The emergence of Anaplasmataceae as human pathogens has gained the attention of scientific 72 community. A recent surveys have shown human infection with anaplasmosis including in 73 Venezuela [15] and one in Morocco where dog owners were infected with A. phagocytophilum $74[16]$.

75 Recent reports on animal anaplasmosis are available from France, Massachusetts, Brazil, Zambia 76 Ethiopia and Kenya in both domestic and wild animals [17-22]. While Anaplasma in NHPs has 77 been reported in some countries, its importance in NHPs in Kenya is not yet known which has 78 therefore led us to investigate the occurrence of this bacteria in NHPs in Laikipia, Kenya.

79 The investigation focused on blood DNA presence of A. phagocytophilum in Olive baboons (Papio 80 anubis) and Vervet monkeys (Chlorocebus pygerythrus) in Laikipia County, Kenya. Laikipia is 81 part of Kenya's rangelands mainly inhabited by trans-human pastoralists. It also has a large 82 wildlife population including primate species. These animals are found close to human settlements. 83 The objectives of this present study were (i) to assess the prevalence of $A$. phagocytophilum in 84 Olive baboons and Vervet monkeys and (ii) to establish whether the bacteria is genetically diverse.

\section{Methods}

\section{Study area, sample population and sample size}


87 This study was part of the USAID Predict II project whose aim was to collect targeted information

88 to support the interventions to mitigate spread of zoonotic viruses with pandemic potential. The

89 focus was on highest risk locations and interfaces, where animals and people share changing

90 landscapes. The study area, Laikipia County (Figure 1) located in the Rift Valley of Kenya with

91 co-ordinates of $005^{\prime} \mathrm{N} 36040^{\prime} \mathrm{E}$, was picked as one of the locations. There is a diverse range of

92 wildlife in the area, including NHPs with 8 species of them found in the area.

$93 \quad$ Figure 1: Map of the sampling sites.

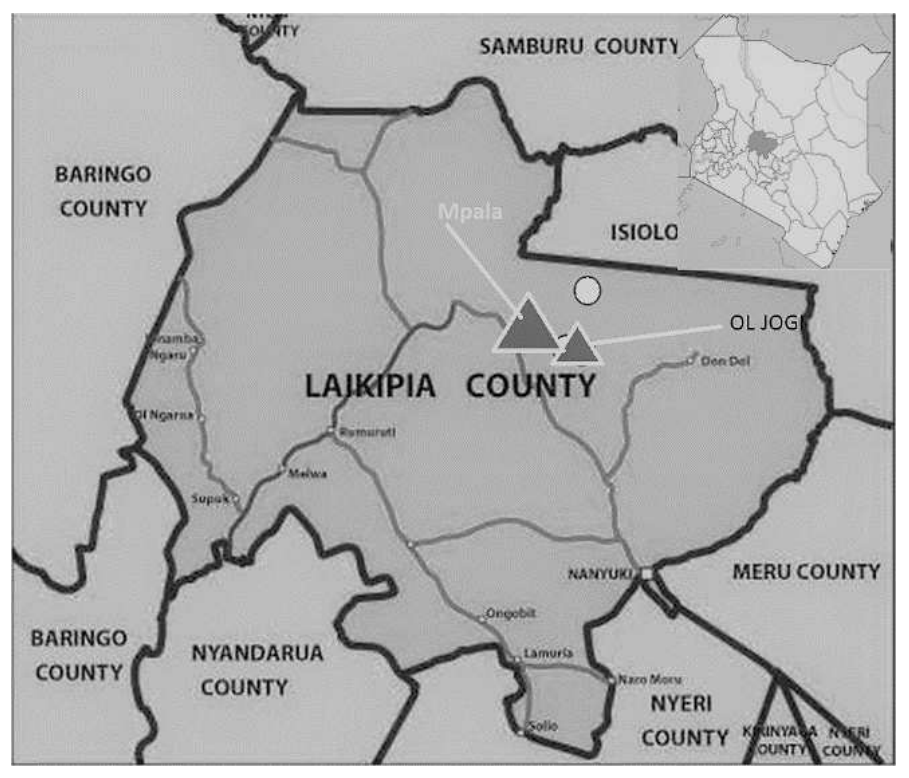

96 This study focused on two NHP species: Olive baboons (Papio anubis) and Vervet monkeys

97 (Chlorocebus pygerythrus), since they are closely related to humans phylogenetically and are

98 implicated in most of the listed emerging human pathogens. The sampling sites Mpala research

99 Centre and Ol jogi Conservancy (Figure 1) were conveniently chosen as large numbers of these

100 species inhabit these sites. All the whole blood samples from wild Olive baboons and Vervet 101 monkeys that had been collected by USAID Predict II project from Laikipia County were included

102 in this study constituting the study's sample size of 146 Olive baboon and 18 Vervet monkey. The 103 animals were not owned. 
105 Whole blood samples stored in TRIzol reagent at $-80^{\circ} \mathrm{c}$ were retrieved and allowed to thaw at room 106 temperature. Extraction of genomic DNA from each of the whole blood sample was done using 107 the DNeasy Blood \& Tissue Kit (Qiagen, Valencia, California, USA) following manufacturer's 108 instructions.

\section{Nested PCR}

110 First set of primers (p3709-p4257) were used in a nested PCR run for amplifying the p44 gene of 111 Anaplasma species in Olive baboons and Vervet monkeys (Table 1). Using the second set of 112 primers (p3761-p4183), 1ul of the product from the first amplification was used in a 25ul reaction

113 mixture. Reactions were performed in a final volume containing 18.25ul double distilled 114 RNase/DNase free water, 2.5ul PCR buffer, 0.75ul 1.5 Mm Mgcl, 0.5 ul of 10um DNTPs, 0.5ul of 115 10um forward primer, $0.5 \mathrm{ul}$ of $10 \mathrm{um}$ reverse primer, $0.1 \mathrm{ul}$ of $2.5 \mathrm{U}$ Taq DNA polymerase and $1.0 \mathrm{ul}$ 116 of the DNA template. Thermal cycling profiles were as previously described [23].

\section{Conventional PCR}

118 The primer set EHR16SD/R was used in a simple PCR to amplify 345bp fragment of Anaplasma 119 16S rRNA gene on the same samples with thermo-cycling profile as previously described [24]. 120 PCR products were electrophoresed on $1 \%$ agarose gel to check the size of amplified fragments 121 by comparison with a DNA molecular weight marker (1 Kb Plus DNA Ladder, Promega, Madison, 122 USA).

\section{DNA sequencing and data analysis}

124 Ten selected positive Anaplasma spp. PCR products obtained with primers EHR16SD/R were 125 purified with Thermo Scientific GeneJET PCR Purification Kit\#K0701, \#K0702 Protocol 
126 according to the manufacturer's instructions. Purified DNA fragments were sequenced using an

127 ABI PRISM 377 Genetic Analyzer (Applied Biosystems, USA), using the same forward and 128 reverse primers (Table 1) of each PCR assay. Sequence assembly for forward and reverse primers 129 was done using DNA Sequence Assembler v4 (2013), Heracle BioSoft [25]. The sequences were 130 matched to those deposited in the GenBank database using BLAST search 131 (http://blast.ncbi.nlm.nih.gov/Blast.cgi). Multiple alignment of the sequences was done using 132 BioEdit Sequence Alignment Editor (Hall, T.A. 1999). Construction of phylogenetic tree was 133 done using Muscle 3.8 using the neighbor-joining method and visualization of the trees with 134 FigTree v1.4.4 [26].

135 All methods were carried out in accordance with relevant guidelines and regulations.

\section{Results}

\section{Molecular survey of Anaplasma species}

A total of 164 blood samples 146 from Olive Baboons and 18, Vervet monkeys where screened for A. phagocytophilum through nested PCR employing the two sets of primers for p44 genes (Table 1). However, all these samples tested negative. A re-run and troubleshooting was done to confirm the results still turned out negative. With the same samples, a different assay and conventional PCR using primers targeting 16S rRNA gene (Table 1), it amplified a specific band of approximately 345bp. The overall prevalence for anaplasmosis was $18.3 \%(30 / 164)$ as estimated by EHR16SD/R PCR (Table 1) with $17.8 \%$ and $22.2 \%$ in Olive baboons and Vervet monkeys respectively.

Table 1: Primers used for detection and/or characterization of Anaplasma species in the present study 


\begin{tabular}{llllll}
\hline Assay & Primer & Sequence 5' to 3' & $\begin{array}{l}\text { Target } \\
\text { gene }\end{array}$ & $\begin{array}{l}\text { Amplicon } \\
\text { size(bp) }\end{array}$ & References \\
\hline Nested PCR & & & & & \\
PCR 1 & p3709 & GCTAAGGAGTTAGCTTATGA & $\mathrm{p} 44$ & 400 & {$[17]$} \\
& $\mathrm{p} 4257$ & AGAAGATCATAACAAGCATTG & & & \\
& & & & & \\
PCR 2 & $\mathrm{p} 3761$ & CTGCTCTKGCCAARACCTC & $\mathrm{p} 44$ & 300 & {$[17]$} \\
& $\mathrm{p} 4183$ & CAATAGTYTTAGCTAGTAACC & & & \\
\hline $\begin{array}{l}\text { Conventional } \\
\text { PCR }\end{array}$ & EHR16SD & GGTACCYACAGAAGAAGTCC & $16 \mathrm{~S}$ & 345 & {$[18]$} \\
& EHR16SR & TAGCACTCATCGTTTACAGC & rRNA & &
\end{tabular}

Molecular characterization of Anaplasma phagocytophilum. 16S rRNA genotypes

152 Nine of the 10 PCR products were successfully sequenced on both DNA strands and generated 153 nucleotide sequences with primers EHR16SD/R targeting 345bp of the 16S rRNA gene of 154 Anaplasma spp. Multiple alignment of Anaplasma nucleotide sequences of 4 A. phagocytophilum 155 isolates revealed that all the sequences were conserved except one 15A which was the most 156 divergent in comparison to the rest with a lot of accumulated mutations and numerous insertions. 157 They all shared $99 \%$ to $100 \%$ nucleotide similarity except $15 \mathrm{~A}$ at $81 \%$ (Table 2).

Table 2: BLASTn analysis results using 16S rRNA sequences of isolates from Olive baboons and Vervet 159 monkeys.

\begin{tabular}{|l|l|l|l|l|}
\hline $\begin{array}{l}\text { Samples } \\
\text { sequences }\end{array}$ & Animal species & Homologous sequences & E values & Identity (\%) \\
\hline $15 \mathrm{~A}$ & Olive Baboons & A.phagocytophilum & 5 & 81.65 \\
\hline 41A & Olive Baboons & A.phagocytophilum & 4 & 99.39 \\
\hline $39 \mathrm{~A}$ & Olive Baboons & A.phagocytophilum & 3 & 99.39 \\
\hline 28A & Olive Baboons & A.phagocytophilum & 4 & 100 \\
\hline
\end{tabular}


160 The sequences of the A. phagocytophilum isolates from Kenya were identical to those from Japan,

161 South Korea, France, China, South Africa and Denmark. The species isolates were from human,

162 cattle, ticks, dogs and rodents. The accession numbers were JQ622148.1, MF351963.1,

$163 \quad$ KU559922.1, MG519284.1, KX810088.1, MH122888.1, MK814411.1, MK814407.1,

$164 \quad$ MF582329.1, $\quad$ MK814412.1, $\quad$ MK271308.1, $\quad$ MH122891.1, AY776165.1, KT986058.1,

165 KU513793.1, and KR611718.1 (Figure 2). Phylogenetic analysis revealed that the isolates from

166 Japan, South Korea, France, China, South Africa and Denmark belonged to clade I but have recent

167 common ancestor with the Kenyan isolates clustered into one clade II except isolate 15A which

168 appeared separately and represented an outgroup (Figure 3).

169 Figure 2: Multiple sequence alignment of 16S rRNA gene for A. phagocytophilum isolates.

\begin{tabular}{|c|c|}
\hline Contig_l5A & CTTGCTCCCAGCTACTTTCGCACCTCAGCGTTAGTACCGGACCATTATTGCCGGGCGTTCAGG.CCACGTAGG \\
\hline Contig_28. & $. G \ldots C A G \ldots, \ldots G, G G, A A T \ldots G G A G, G, G C, A G C G T T, T T, G G A \ldots A T T \ldots \ldots A A \ldots G \ldots T \ldots$ \\
\hline Contig_39A & . GGAG.G.GC.AGCGTT,TT,GGA...ATT. \\
\hline Contig_4lA & .GGAG.G.GC.AGCGTT.TT.GGA...ATT.... \\
\hline JQ622148.1 & . GGAG.G.GC.AGCGTT.TT.GGA...ATT.... \\
\hline MF351963.1 & $. G \ldots C A G \ldots . C G, G G, A A T \ldots G G A G, G, G C, A G C G T T, T T, G G A \ldots A T T \ldots \ldots A A \ldots G$. \\
\hline KU559922.1 & 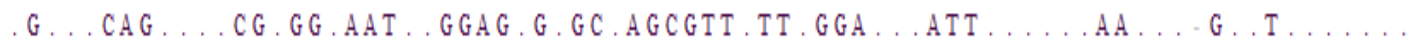 \\
\hline MG519284.1 & .GGAG.G.GC.AGCGTT.TT.GGA. \\
\hline KX810088.1 & $. G \ldots C A G \ldots . C G, G G, A A T \ldots G G A G, G, G C, A G C G T T, T T, G G A \ldots A T T \ldots \ldots A A \ldots G$. \\
\hline MHl22888.1 & $G \ldots C A G \ldots C G, G G . A A T \ldots G G A G, G, G C . A G C G T T . T T . G G A \ldots A T T \ldots \ldots A A \ldots G$. \\
\hline MK814411.1 & $. G \ldots C A G \ldots . C G, G G . A A T \ldots G G A G, G, G C, A G C G T T . T T . G G A \ldots A T T \ldots \ldots A A$ \\
\hline MK814407.1 & $. G \ldots C A G \ldots . C G, G G, A A T \ldots G G A G, G, G C, A G C G T T . T T, G G A \ldots A T T \ldots \ldots A A \ldots G$. \\
\hline MF582329.1 & $. G \ldots C A G \ldots . \ldots G, G G, A A T \ldots G G A G, G, G C, A G C G T T . T T, G G A \ldots A T T \ldots$ \\
\hline MK814412.1 & $. G \ldots C A G \ldots . C G, G G, A A T \ldots G G A G, G, G C, A G C G T T, T T, G G A \ldots A T T \ldots \ldots A A$ \\
\hline MK271308.1 & $. G \ldots C A G \ldots . C G, G G, A A T, G G A G, G, G C, A G C G T T, T T, G G A \ldots A T T \ldots \ldots A A$ \\
\hline MHl22891.1 & $. G \ldots C A G \ldots . \ldots G, G G, A A T \ldots G G A G, G, G C, A G C G T T, T T, G G A$ \\
\hline AY776165.1 & $. G \ldots C A G \ldots, C G, G G, A A T \ldots G G A G, G, G C, A G C G T T, T T, G G A$ \\
\hline KT986058.1 & $. G \ldots, \ldots A G \ldots . . C G, G G . A A T \ldots G G A G, G, G C, A G C G T T . T T . G G A \ldots$ \\
\hline KU513793.1 & $. G \ldots, \ldots A G \ldots . . C G, G G, A A T, . G G A G, G, G C, A G C G T T, T T, G G A \ldots$ \\
\hline KR611718.1 & $. G \ldots C A G \ldots, \ldots G, G G, A A T, G G A G, G, G C, A G C G T T, T T, G G A \ldots A T T \ldots$ \\
\hline
\end{tabular}

171 The conserved regions are represented by the dots (.) while the variable regions are indicated by the letters

172 representing the nucleotide $\mathrm{A}, \mathrm{C}, \mathrm{G}$ and $\mathrm{T}$ 
Figure 3: Phylogenetic tree of the $16 \mathrm{~S}$ rRNA gene from A.phagocytophilum isolates.

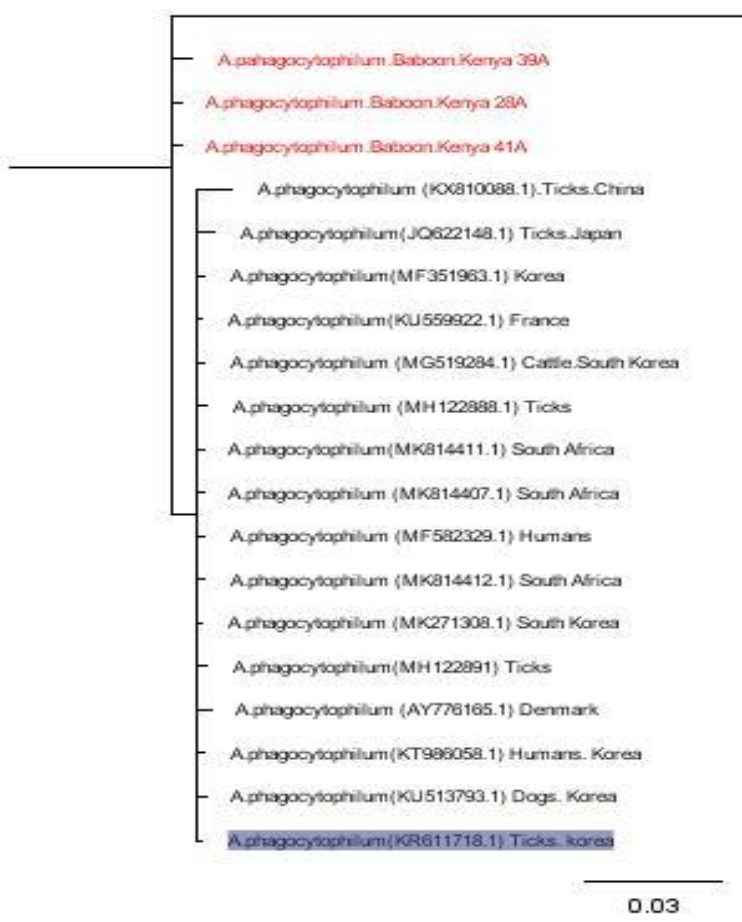

\section{Discussion}

177 An epidemiological surveillance of pathogens in NHPs found at the human-animal interface is

178 important in developing strategies on prevention and control of emerging and re-emerging

179 zoonotic diseases.

180 Therefore, this study reports the detection of A. phagocytophilum DNA within the studied localities

181 with an overall prevalence of $18.3 \%$. A. phagocytophilum, an obligate intracellular bacterium, is

182 the agent of human granulocytic anaplasmosis, formerly known as human granulocytic ehrlichiosis

183 [13]. A. phagocytophilum has been previously reported to infect a wide range of animal hosts in

184 various parts of the world [17-19], in Africa, [20, 27] while in Kenya [21, 22, 28, 29]. This study

185 adds further evidence on the occurrence of $A$. phagocytophilum in Olive baboons and Vervet

186 monkeys in Kenya. 
187 In this study, a total of 164 samples were tested and an overall prevalence for anaplasmosis was $188 \quad 18.3 \%$ and $17.8 \%$ and $22.2 \%$ in Olive baboons and Vervet monkeys respectively which was similar to that reported in a survey on cattle in Ethiopia [27]. This is however inconsistent with reports by 190 other authors. For example, in Zambia reported a 13\% prevalence in baboons and Rhesus 191 macaques [20]. In Kenya, a study on Anaplasma hemoparasites in wild animals revealed high 192 seroprevalence [29] while another reported 35.5\% sero-prevalence in cattle in Nairobi, Kenya [22]. 193 Studies have shown that A. phagocytophilum can persist for the lifetime of animals due to its effect 194 on the glucose metabolic pathways for maintenance of infection and multiplication [30]. This 195 explains the high detection rates of Anaplasma infection in certain animal populations. Different 196 host species, sample sizes, diagnostic technique, study areas demography and endemicity disease 197 status in each study region could also explain it.

198 In this study, primers targeting p44 and 16S rRNA genes of A. phagocytophilum were identified 199 from previous studies and used for detection of $A$. phagocytophilum $[23,24]$. However, there was 200 a significant difference in the performance of these two assays. The primers targeting p44 gene 201 did not yield any positive bands on PCR. This is in agreement with several studies in cattle [27], 202 wild birds and bats [31] and in ruminants and ticks [32]. This can be explained by the high 203 variability of p44 gene, which includes intra-species variability, with consequent protein 204 polymorphism and the generation of antigenic variations [33, 34]. The 16S rRNA gene yielded 205 positive bands and therefore reinforced that it is a good marker for detection of Anaplasma as 206 reported by other studies $[20,27,35]$.

207 Further sequencing analysis revealed that the sequences of $16 \mathrm{~S}$ rRNA were very conserved not 208 only between African isolates but also between the other isolates of world-wide origin agreeably 209 with previous studies [36]. The sequences of the A. phagocytophilum isolates from Kenya were 
210 identical to those from Japan, South Korea, France, China, South Africa and Denmark. The species

211 isolates were from human, cattle, ticks, dogs and rodents (Figure 3). This is consistent with a study

212 on baboons in Zambia [20]. Multiple alignment of Anaplasma nucleotide sequences of the

213 A.phagocytophilum isolates revealed that all the sequences of samples from baboons were

214 conserved except for 15A. It was the most divergent in comparison to the rest with a lot of

215 accumulated mutations and numerous insertions (Figure 2).

216 Extensive molecular studies have enabled understanding of the genetic profiles, level of genetic

217 relatedness or variations among isolates across the different geographical regions and animal

218 species. The isolates from Japan, South Korea, France, China, South Africa and Denmark belonged

219 to clade I but have recent common ancestor with the Kenyan isolates clustered into one clade II

220 except isolate 15A which appeared separately and represented a kind of outgroup (Figure 3).

221 Previous studies have reported genetic relatedness between A. phagocytophilum infecting animals

222 and humans [15, 35]. Similarly, in this study isolates from Olive baboons appear to be genetically

223 related to those of human (MF582329.1) (Figure 3).

224 This, to the best of our knowledge, this is among the first molecular detection and estimate of the 225 prevalence of Anaplasma phagocytophilum in Kenya's Olive baboons and Vervet monkeys. Non-

226 human primates have been shown to host different pathogens, including several Anaplasma species

$227[34,20]$. We assume that they could serve as a good indicator of bacteria circulation in ecosystem 228 and explain the persistence of anaplasmosis in domestic animals despite consistence control.

This paper reports the presence of novel Anaplasma phagocytophilum in Olive baboons and Vervet 
235 information to elucidate the evolutionary history of bacterial species related to $A$. 236 phagocytophilum. Further studies are needed to investigate the role of Olive baboons and Vervet 237 monkeys in the maintenance of Anaplasma organisms to establish the public health implications 238 of zoonotic A. phagocytophilum isolates.

\section{Abbreviations}

240 NHPs: Nonhuman primates

241 USAID: United States AID

242 PCR: Polymerase chain reaction

243 DNA: Deoxyribonucleic acid

244 RNA: Ribonucleic acid

245 rRNA: Ribosomal Ribonucleic acid

246 EIDs: Emerging infectious diseases

247 HGA: Human granulocytic anaplasmosis

248 OR: Odds ratio

249 CL: Confidence level

250 CI: Confidence interval

251 DNTPs: Deoxyribonucleotide triphosphate

252 BLAST: Basic Local Alignment Search Tool

253 Msp: Major Surface Protein 


\section{$254 \quad$ References}

255

256

257

258

259

260

261

262

263

264

265

266

267

268

269

270

271

272

273

274

275

276
1. Heymann, D. L. et al. (2015). Global health security: the wider lessons from the West African Ebola virus disease epidemic. Lancet 385, 1884-1901

2. Jones B.A., Grace D., Kock R., Alonso S., Rushton J., and Said M.Y., McKeever D., Mutua F., Young J., McDermott J. \& Pfeiffer D.U. (2013): Zoonosis emergence linked to agricultural intensification and environmental change. Proc. natl Acad. Sci. USA, 110: 8399-8404.

3. Brierley, L., Vonhof, M. J., Olival, K. J., Daszak, P. \& Jones, K. E. (2016). Quantifying global drivers of zoonotic bat viruses: a process-based perspective. Am. Nat 187, E53-E64

4. Locatelli, S. \& Peeters, M. (2012) Non-Human Primates, Retroviruses, and Zoonotic Infection Risks in the Human Population. Nature Education Knowledge 3(10):62

5. Jones-Engel L, May CC, Engel GA, Steinkraus KA, Schillaci MA, et al. (2008): Diverse contexts of zoonotic transmission of simian foamy viruses in Asia.

6. Allen, T., Murray, K.A., Zambrana-Torrelio, C. et al. Global hotspots and correlates of emerging zoonotic diseases. Nat Commun 8, 1124 (2017). https://doi.org/10.1038/s41467017-00923-8

7. Ismail N, Bloch KC and McBride JW (2010): Human ehrlichiosis and anaplasmosis. Clinics in Laboratory Medicine 30; 261-292.

8. Dumler, J. S., A. F. Barbet, C. P. J. Bekker, G. A. Dasch, G. H. Palmer, S. C.Ray, Y. Rikihisa, and F. R. Rurangirwa (2001): Reorganization of the genera in the families Rickettsiaceae and Anaplasmataceae in the order Rickettsiales: unification of some species of Ehrlichia with Anaplasma, Cowdria with Ehrlichia and Ehrlichia with Neorickettsia, 
descriptions of six new species combination and designation of Ehrlichia equi and 'HGE agent'

9. Wuritu, et al. (2009): Structural analysis of a p44/msp2 expression site of Anaplasma phagocytophilum in naturally infected ticks in Japan. J. Med. Microbiol. 58:1638-1644.

10. Lin Q, Rikihisa Y, Felek S, Wang X, Massung RF, Woldehiwet Z (2004): Anaplasma phagocytophilum has a functional msp2 gene that is distinct from $\mathrm{p} 44$. Infection and Immunity 72, 3883-3889.

11. Foley J. E., et al. (2009): Distinct ecologically relevant strains of Anaplasma 285 phagocytophilum Emerg. Infect. Dis. 15:842-843

12. Kocan, Katherine \& de la Fuente, Jose \& Cabezas-Cruz, Alejandro (2015): The genus Anaplasma: New challenges after reclassification. Revue scientifique et technique (International Office of Epizootics). 34: 577-586.

13. Bakken JS, Dumler JS, Chen SM, Eckman MR, Van Etta LL, Walker DH. Human granulocytic ehrlichiosis in the upper Midwest United States. A new species emerging? JAMA. 1994 Jul 20; 272 (3):212-8. PMID: 8022040.

14. Zaid, T., Ereqat, S., Nasereddin, A., Al-Jawabreh, A., Abdelkader, A., \& Abdeen, Z. (2019). Molecular characterization of Anaplasma and Ehrlichia in ixodid ticks and reservoir hosts from Palestine: a pilot survey. Veterinary Medicine and Science. doi:10.1002/vms3.150

15. Arraga-Alvarado CM, Qurollo BA, Parra OC, Berrueta MA, Hegarty BC, Breitschwerdt EB. Case report: Molecular evidence of Anaplasma platys infection in two women from Venezuela. Am J Trop Med Hyg. 2014 Dec; 91(6):1161-5. doi: 10.4269/ajtmh.14-0372. Epub 2014 Sep 29. PMID: 25266347; PMCID: PMC4257640. 
16. Elhamiani Khatat, S., Daminet, S., Kachani, M. et al. (2017) Anaplasma spp. in dogs and owners in north-western Morocco. Parasites Vectors 10, 202 doi:10.1186/s13071-017$2148-\mathrm{y}$

17. Afonso E, Goydadin A-C (2018). Molecular detection of Anaplasma phagocytophilum DNA in the lesser horseshoe bat (Rhinolophus hipposideros) guano. Epidemiology and Infection 146,1253-1258.https://doi.org/10.1017/S0950268818001279

18. Galemore, E. R., Labato, M. A., \& O’Neil, E. (2018): Prevalence of Anaplasma phagocytophilum infection in feral cats in Massachusetts. Journal of Feline Medicine and Surgery Open Reports,

19. Silveira, J. A. G., Rabelo, E. M. L., \& Ribeiro, M. F. B. (2011). Molecular Detection of Tick-Borne Pathogens of the Family Anaplasmataceae in Brazilian Brown Brocket Deer (Mazama gouazoubira, Fischer, 1814) and Marsh Deer (Blastocerus dichotomus, Illiger, 1815). Transboundary and Emerging Diseases, 59(4), 353-360.

20. Nakayima J, Hayashida K, Nakao R, Ishii A, Ogawa H, Nakamura I, Moonga L, Hang'ombe BM, Mweene AS, Thomas Y, Orba Y, Sawa H, Sugimoto C (2014):Detection and characterization of zoonotic pathogens of free-ranging non-human primates from Zambia. Parasit Vectors 7:490

21. Kitaa, Jafred. (2014): A retrospective Study of Canine Ehrlichiosis in Kenya. International Journal of Veterinary Science. 3. 122-124

22. Peter SG, Gakuya DW, Maingi N, Mulei CM (2019) Prevalence and risk factors associated with Ehrlichia infections in smallholder dairy cattle in Nairobi City County, Kenya, Veterinary World, 12(10): 1599-1607. 
23. Lin, Q., N. Zhi, N. Ohashi, H. W. Horowitz, M. E. Aguero-Rosenfeld, J. Ruffalli, G. P. Wormser, and Y. Rikihisa. 2002. Analysis of sequences and loci of p44 homologs expressed by Anaplasma phagocytophila in acutely infected patients. J. Clin. Microbiol. 40:2981-2988.

24. Parola, Philippe \& Roux, Veronique \& Camicas, J \& Baradji, Issa \& Brouqui, Philippe \& Raoult, Didier. (2000). Detection of Ehrlichiae in African ticks by polymerase chain reaction. Transactions of the Royal Society of Tropical Medicine and Hygiene. 94. 707-8. 10.1016/S0035-9203(00)90243-8.

25. DNA Baser Database. https://www.dnabaser.com/download/DNA-Baser-sequenceassembler/index.html. Assessed 13 June 2020.

26. Molecular Evolution, Phylogenetics and Epidemiology. http://tree.bio.ed.ac.uk/. Assessed 20 June 2020.

27. Teshale, S., Geysen, D., Ameni, G., Dorny, P., \& Berkvens, D. (2018). Survey of Anaplasma phagocytophilum and Anaplasma sp. "Omatjenne" infection in cattle in Africa with special reference to Ethiopia. Parasites \& Vectors, 11(1).

28. Wesonga F.D., Kitala P.M., Gathuma J.M., Njenga M.J., Ngumi P.N. (2010): An assessment of tick-borne diseases constraints to livestock production in a smallholder livestock production system in Machakos district, Kenya. Livest. Res. Rural Dev; 22

29. Ngeranwa, J., Shompole, S., Venter, E., Wambugu, A., Crafford, J., \& Penzhorn, B. (2008). Detection of Anaplasma antibodies in wildlife and domestic species in wildlife-livestock interface areas of Kenya by major surface protein 5 competitive inhibition enzyme-linked immunosorbent assay. Onderstepoort Journal of Veterinary Research, 75(3), 199-205. doi: https://doi.org/10.4102/ojvr.v75i3.95 
30. Cabezas-Cruz, A., Espinosa, P. J., Obregón, D. A., Alberdi, P., \& de la Fuente, J. (2017). Ixodes scapularis Tick Cells Control Anaplasma phagocytophilum Infection by Increasing the Synthesis of Phosphoenolpyruvate from Tyrosine. Frontiers in Cellular and Infection Microbiology, 7. doi:10.3389/fcimb.2017.00375

31. dos Santos LGF, Ometto T, de Araújo J, Thomazelli LM, Borges LP (2013) Absence of Anaplasmataceae DNA in Wild Birds and Bats from a flooded Area in the Brazilian Northern Pantanal. Air Water Borne Diseases 2: 113. doi:10.4172/2167-7719.1000113

32. Yang, Jifei \& Liu, Zhijie \& Qingli, Niu \& Liu, Junlong \& Xie, Jingying \& Chen, Qiuyu \& Chen, Ze \& Guan, Guiquan \& Liu, Guangyuan \& Luo, Jianxun \& Yin, Hong. (2016). Evaluation of different nested PCRs for detection of Anaplasma phagocytophilum in ruminants and ticks. BMC Veterinary Research. 12. 10.1186/s12917-016-0663-2.

33. Barbet AF, Lundgren AM, Alleman AR, Stuen S, Bjöersdorff A, Brown RN, Drazenovich NL, Foley JE. Structure of the expression site reveals global diversity in MSP2 (P44) variants in Anaplasma phagocytophilum. Infect Immun. 2006 Nov; 74 (11):6429-37. doi: 10.1128/IAI.00809-06. Epub 2006 Sep 11. PMID: 16966408; PMCID: PMC1695497.

34. Dumler, J. S. (2005): Anaplasma and Ehrlichia Infection. Annals of the New York Academy of Sciences 106: 361-373

35. Elhamiani Khatat, S., Daminet, S., Kachani, M. et al. (2017) Anaplasma spp. in dogs and owners in north-western Morocco. Parasites Vectors 10, 202 doi:10.1186/s13071-017$2148-\mathrm{y}$

36. Zhang L, Wang G, Liu Q, Chen C, Li J, Long B, Yu H, Zhang Z, He J, Qu Z, YuJ, Liu Y, Dong T, Yao N, Wang Y, Cheng X, Xu J (2013): Molecular analysis of Anaplasma 


\section{Declarations}

\section{$370 \quad$ Ethical approval}

371 Approval for this study was given by the Institute of Primate research Institutional Scientific and

372 Ethics Review Committee (ISERC): Ethical approval number 1SERC/T01/18, 17 November.

373 Since the information collected for this study was not of a sensitive nature and non-invasive as

374 only blood samples previously collected were used, the ethical approval and guidelines received

375 from this committee was deemed sufficient to conduct the study.

376 Consent for publication

377 Not applicable.

378 Availability of data and materials

379 Data and materials are available upon reasonable request from the corresponding author.

\section{Competing interests}

381 The authors declare that they have no competing interests.

\section{$382 \quad$ Funding}

383 The work was supported by the funding from the USAID Predict II project, 2018.

\section{Authors' Contributions}


385 SJM conducted the field and laboratory work. In addition, she participated in the study design, did 386 the data analysis and preparation of this manuscript. GMM, JMK, and TAO were involved in the

387 conception of the study, study design and the writing of this manuscript. SKM participated in the

388 laboratory work. All authors have read and approved the final manuscript.

\section{Acknowledgement}

390 We thank the staff at the Molecular Laboratory at the Institute of Primate Research, Kenya who

391 assisted with laboratory analysis of the work. The authors would like to thank Dr. Mercy Akinyi, 392 and Dr. Lilian Waiboci for their invaluable contribution in the work.

393 Authors' information

394 Affiliations

395 1. Department of Public Health, Pharmacology and Toxicology, Faculty of Veterinary

396 Medicine, University of Nairobi, Nairobi, Kenya

$397 \quad$ Sophie Jerusa Masika

398 2. Department of Public Health, Pharmacology and Toxicology, Faculty of Veterinary

399 Medicine, University of Nairobi, Nairobi, Kenya

$400 \quad$ Gerald Mwangi Muchemi

401 3. Reproductive Health and Biology Department, Institute of Primate Research, National 402 Museums of Kenya, Nairobi Kenya. 
404 4. Department of Clinical Studies, Faculty of Veterinary Medicine, University of Nairobi, $405 \quad$ Nairobi, Kenya

Tequiero Abuom Okumu

407 5. Reproductive Health and Biology Department, Institute of Primate Research, National 408 Museums of Kenya, Nairobi Kenya.

409 Samson Kamawe Mutura, Joseph Muiruri Kamau

410 Corresponding author

411 Correspondence to Sophie Jerusa Masika, Tel., +254724855023, Email:

412 masikasophie10@gmail.com 


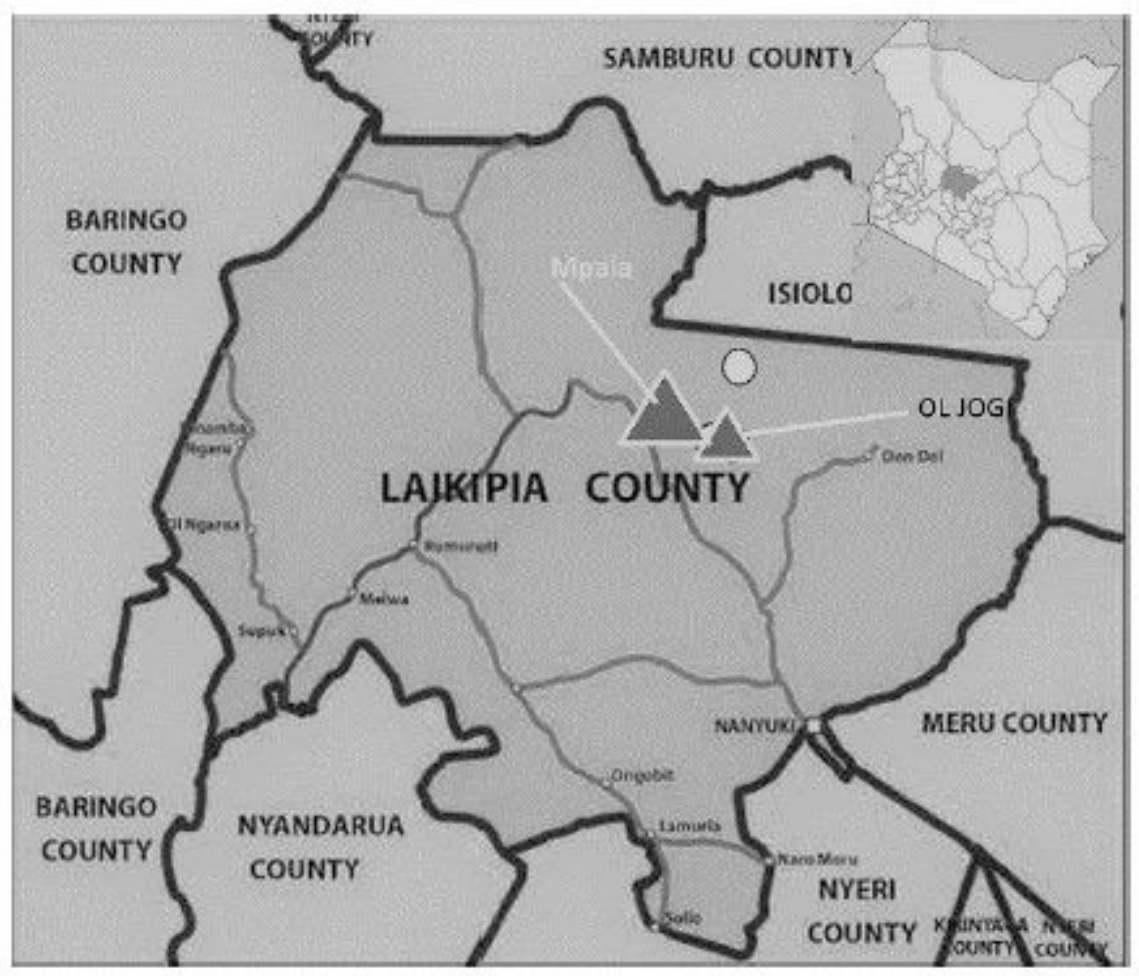

\section{Figure 1}

Map of the sampling sites. Note: The designations employed and the presentation of the material on this map do not imply the expression of any opinion whatsoever on the part of Research Square concerning the legal status of any country, territory, city or area or of its authorities, or concerning the delimitation of its frontiers or boundaries. This map has been provided by the authors.

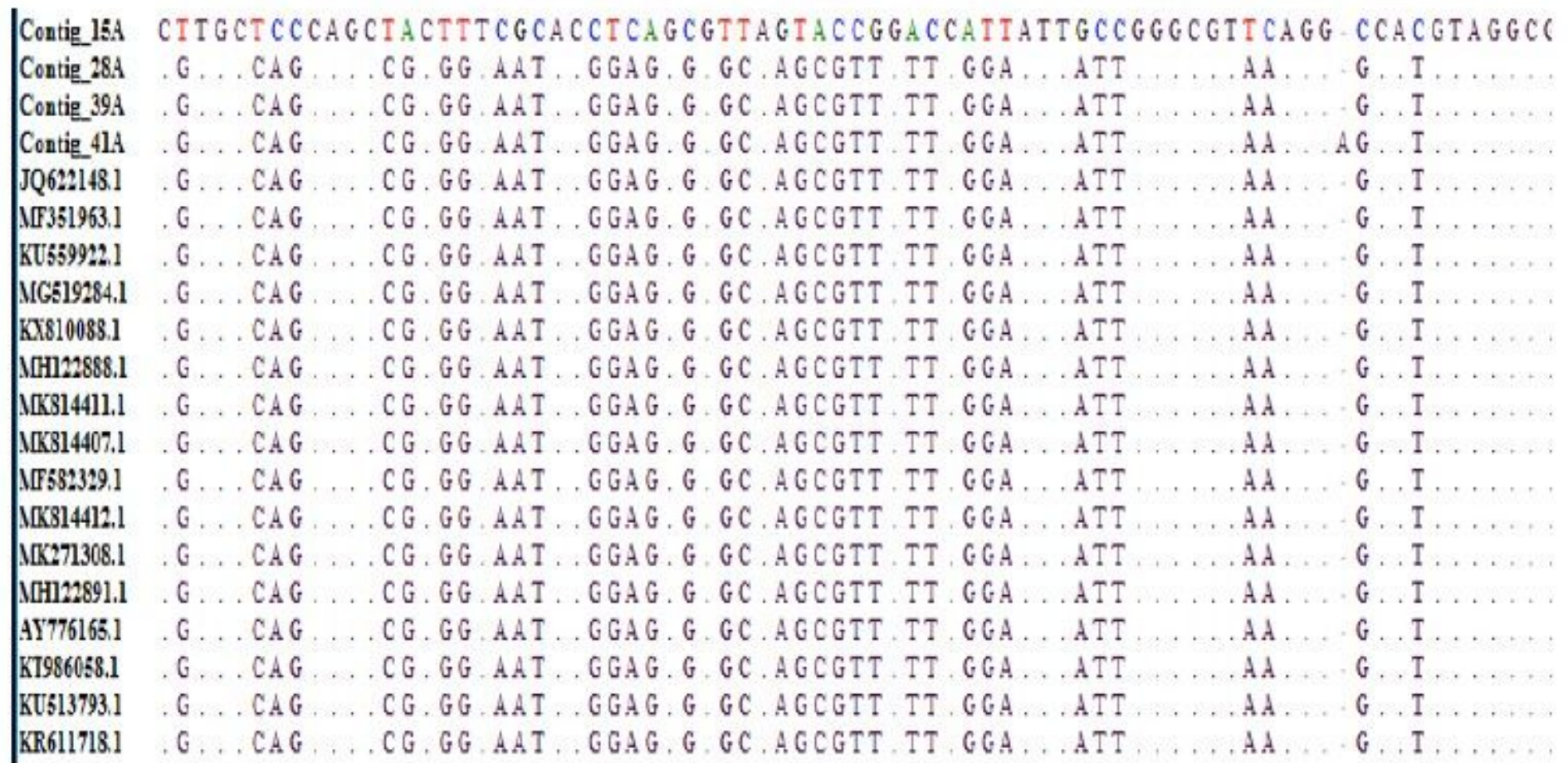




\section{Figure 2}

Multiple sequence alignment of 16S rRNA gene for A. phagocytophilum isolates. The conserved regions are represented by the dots (.) while the variable regions are indicated by the letters representing the nucleotide A, C, G and T

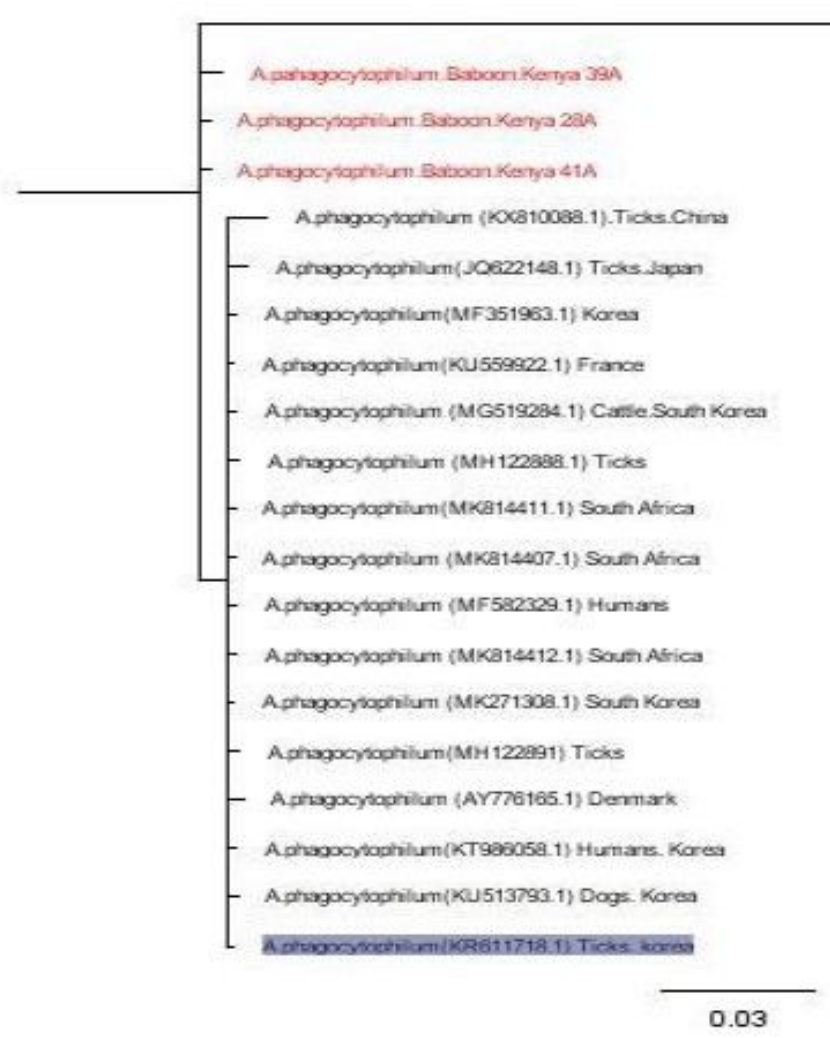

\section{Figure 3}

Phylogenetic tree of the 16S rRNA gene from A.phagocytophilum isolates. 